\title{
Interactions between large and small detritivores influence how biodiversity impacts litter decomposition
}

\author{
Alan M. Tonin ${ }^{1,2}$ (D) | Jesús Pozo ${ }^{2}$ | Silvia Monroy ${ }^{2}$ | Ana Basaguren ${ }^{2}$ | \\ Javier Pérez $^{2}$ | José F. Gonçalves Jr ${ }^{1}$ | Richard Pearson ${ }^{3}$ | Bradley J. Cardinale ${ }^{4}$ | \\ Luz Boyero ${ }^{2,3,5}$
}

${ }^{1}$ Limnology/Aquaripária Lab, Department of Ecology, IB, University of Brasília (UnB), Brasília, Brazil

${ }^{2}$ Faculty of Science and Technology, University of the Basque Country (UPV/ EHU), Leioa, Spain

${ }^{3}$ College of Science and Engineering, and TropWater, James Cook University, Townsville, QLD, Australia

${ }^{4}$ Cooperative Institute for Great Lakes Research (CIGLR), School for Environment and Sustainability, University of Michigan, Ann Arbor, Michigan

${ }^{5}$ IKERBASQUE, Basque Foundation for Science, Bilbao, Spain

\section{Correspondence}

Alan M. Tonin, Limnology/Aquaripária Lab, Department of Ecology, IB, University of Brasilia (UnB), Brasília, Brazil.

Email: tonin.alan@gmail.com

Funding information

Spanish Ministry of Economy and Competitiveness (MINECO) and FEDER, Grant/Award Number: CGL2014-52779-P and BES-2012-060743; Ikerbasque start-up funds; Basque Government funds, Grant/ Award Number: IT302-10; CAPES/Science without Borders, Grant/Award Number: BEX 10178/14-7

Handling Editor: Eoin O'Gorman

\section{Abstract}

1. Understanding how biodiversity loss influences plant litter decomposition-that is, the biologically mediated conversion of coarse to fine particulate organic matteris crucial to predict changes in the functioning of many stream ecosystems, where detrital food webs are dominant. Rates of litter decomposition are influenced by detritivore diversity, but the mechanisms behind this relationship are uncertain.

2. As differences in detritivore body size are a major determinant of interspecific interactions, they should be key for predicting effects of detritivore diversity on decomposition. To explore this question, we manipulated detritivore diversity and body size simultaneously in a microcosm experiment using two small (Leuctra geniculata and Lepidostoma hirtum) and two large detritivore species (Sericostoma pyrenaicum and Echinogammarus berilloni) in all possible 1-, 2- and 4-species combinations, and litter discs of Alnus glutinosa.

3. We expected that larger species would facilitate smaller species through the production of smaller litter fragments, resulting in faster decomposition and greater growth of smaller species in polycultures containing species of different body size. To examine this hypothesis, we used a set of "diversity-interaction" models that explored how decomposition was affected by different interspecific interactions and the role of body size, and quantified the magnitude of such effect through ratios of decomposition rates and detritivore growth between polycultures and monocultures.

4. We found a clear positive effect of detritivore diversity on decomposition, which was mainly explained by facilitation and niche partitioning. Facilitation of small animals by larger ones was evidenced by a $12 \%$ increase in decomposition rates in polycultures compared to monocultures and the higher growth (20\%) of small species, which partly fed on fine particulate organic matter produced by larger animals. When the large species were together in polycultures, decomposition was enhanced by $19 \%$, but there were no changes in growth; niche partitioning was a plausible mechanism behind the increase in decomposition rates, as both species fed on different parts of litter discs, only one species being able to eat less palatable parts. 
5. Our study demonstrates that interspecific differences in body size should be taken into account in diversity-decomposition studies. Future studies should also consider differences in species' vulnerability to extinction depending on body size and how this might affect ecosystem functioning in different scenarios of detritivore diversity and more complex food webs.

\section{KEYWORDS}

body size, detritivore assemblages, ecosystem functioning, facilitation, resource partitioning, species richness, streams

\section{1 | INTRODUCTION}

Rapid loss of biodiversity is of major global concern, partly because of its potential consequences for ecosystem processes and the services they provide to humans (Cardinale et al., 2012). Motivated by this concern, hundreds of experimental studies have been conducted across a wide variety of organisms and systems and have confirmed that changes in species richness can alter key ecosystem process rates (Balvanera et al., 2006; Cardinale et al., 2006, 2011). However evidence is not consistent for different ecosystem processes: while it is well-established that plant diversity boosts primary production, the relationship between biodiversity loss and plant litter decomposition is still unclear, especially because less work has been performed on detritivore diversity than for other trophic levels and functions (Cardinale et al., 2011). Understanding this relationship is a crucial research goal if we are to predict the consequences of diversity loss on global carbon and nutrient cycles, as $90 \%$ of the plant biomass produced annually becomes plant litter and a considerable amount of it is ultimately decomposed (Cebrian, 1999).

Decomposition is a process that involves multitrophic biological interactions (Scherer-Lorenzen, 2008) and thus can be affected by the diversity of plants, microbes and detritivores (Gessner et al., 2010). While there is evidence that detritivore diversity has stronger effects on decomposition than plant diversity (Srivastava et al., 2009), the underlying biological mechanisms behind a diversity-decomposition relationship are better known for plant diversity (e.g. Handa et al., 2014). This is partly because plant diversity effects are easily partitioned into complementarity and selection effects, using a statistical approach proposed almost two decades ago [i.e. the additive partitioning method (Loreau \& Hector, 2001)]. In contrast, assessing the contribution of different detritivore species to decomposition in an assemblage requires the use of more sophisticated and new techniques (Kirwan et al., 2009), which are necessary to identify the most plausible mechanisms underlying detritivore diversity effects on decomposition.

Within a detritivore assemblage, the observed net diversity effect on decomposition will depend on a balance between positive and negative interactions between species. The former may include resource partitioning (which can arise if different species exploit litter differently in space or time; Schoener, 1974; Fynke \& Snyder,
2008; Dangles, Carpio, \& Woodward, 2012), facilitation (if a species enhances the performance of another species or both enhance each other's performances; Bruno, Stachowicz, \& Bertness, 2003; Wright, Wardle, Callaway, \& Gaxiola, 2017) and a positive selection effect (if a species with large effects on decomposition dominates the assemblage; Fox, 2005), while negative effects are often associated with competition (mainly when one species is a dominant competitor or shows aggressive behaviour; Creed, Cherry, Pflaum, \& Wood, 2009) and a negative selection effect (if a competitively dominant species does not contribute significantly to decomposition; Jiang, $\mathrm{Pu}, \&$ Nemergut, 2008). Although species identity might mediate biological interactions responsible for biodiversity effects (as commonly evidenced by species assemblage main effects), species functional traits are also of great importance in predicting biodiversity effects on ecosystem functioning (Hooper et al., 2005). Within this context, body size is a relevant animal trait because it is linked to and help understand (a) multiple biological traits such as growth, reproduction and mortality (Peters, 1983); (b) foraging behaviour (Petchey, Beckerman, Riede, \& Warren, 2008); and (c) interspecific interactions including trophic relationships, competition and facilitation (Woodward et al., 2005). Thus, measuring body size is an easy way to condense a great array of biological traits into one predictor (Woodward et al., 2005). To a remarkable degree, interspecific differences in body size have rarely been taken into account when exploring detritivore diversity effects on decomposition (exceptions include Reiss, Bailey, Perkins, Pluchinotta, \& Woodward, 2011 and Dangles et al., 2012).

We explored how detritivore diversity loss affected litter decomposition-as the transformation of coarse leaf litter $(>1 \mathrm{~mm})$ into finer fragments $(<1 \mathrm{~mm})$ due to shredding and feeding activity-in stream microcosms, and investigated the potential biological mechanisms underlying such effects, with a suite of methods used novelly in this context. By manipulating detritivore species body size, and using a set of statistical models ("diversity-interactions models") that explicitly take into account the role of species interactions and differences in body size, we tested the hypothesis that diversity enhances decomposition when species differ in body size because litter processing by larger detritivores facilitates processing by smaller species through the production of smaller litter fragments (Hypothesis 1), while diversity has weaker or no effect 
on decomposition when different species in the assemblage are of similar size because they are more likely to be functionally similar. Unlike the additive partitioning method, this approach does not require measuring the contribution of each species in a polyculture, but identifies the most parsimonious description of diversity effects. Further, we examined the magnitude of diversity effects on decomposition using the ratio of decomposition rates in polycultures:monocultures (an analogue of response ratios), and repeated the procedure with growth rates, as we expected that they would be enhanced in smaller detritivores when facilitation by larger detritivores occurred (Hypothesis 2). Finally, we investigated the nature of detritivore interactions by observing the feeding modes and foraging behaviours of large and small species, and behavioural differences between monocultures and polycultures that might indicate the existence of facilitation.

\section{2 | MATERIALS AND METHODS}

\section{1 | Detritivore species}

We selected four common detritivore species in our study area (the Agüera catchment in northern Spain, $43.25^{\circ} \mathrm{N} 3.26^{\circ} \mathrm{W}$ ) to represent "small" and "large" organisms. Small detritivores were the stonefly Leuctra geniculata Stephens, 1835 (Leuctridae) and the caddisfly Lepidostoma hirtum Fabricius, 1775 (Lepidostomatidae) (hereafter Leuctra and Lepidostoma); large detritivores were the caddisfly Sericostoma pyrenaicum Pictet, 1865 (Sericostomatidae) and the amphipod Echinogammarus berilloni Catta, 1878 (Gammaridae) (hereafter Sericostoma and Echinogammarus) (Basaguren, Riaño, \& Pozo, 2002; Larrañaga, Basaguren, \& Pozo, 2014; Riaño, 1998). Average body dry mass $\pm S E$ was $0.7 \pm 0.1 \mathrm{mg}$ for Leuctra, $2.3 \pm 0.1 \mathrm{mg}$ for Lepidostoma, $7.5 \pm 0.2 \mathrm{mg}$ for Sericostoma and $6.1 \pm 0.1 \mathrm{mg}$ for Echinogammarus. Detritivores were collected in June 2015 from leaf litter in streams. They were transported in aerated containers within a cooler and kept in a controlled temperature room set at $10^{\circ} \mathrm{C}$, which was lower than the average temperature of streams when detritivores were collected $\left(\right.$ c. $13^{\circ} \mathrm{C}$ ) but similar to the average annual temperature of those streams and within the temperature range in June (unpubl. data), and significantly reduced evaporation during the experiment. Detritivores were starved for $48 \mathrm{hr}$ prior to the experiment.

\section{2 | Experimental set-up}

Our experiment included all possible 1-, 2- and 4-species combinations, which resulted in 11 treatments (i.e. four monocultures; six 2-species polycultures, 2 with 1 and 4 with 2 body-size categories;

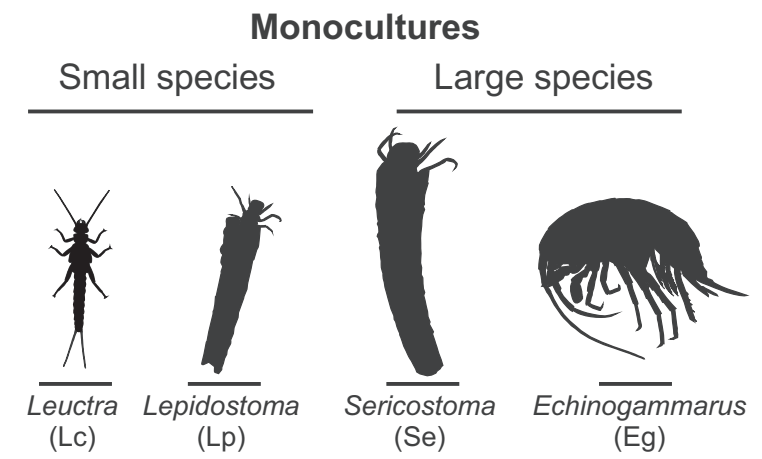

\section{2-Species polycultures}

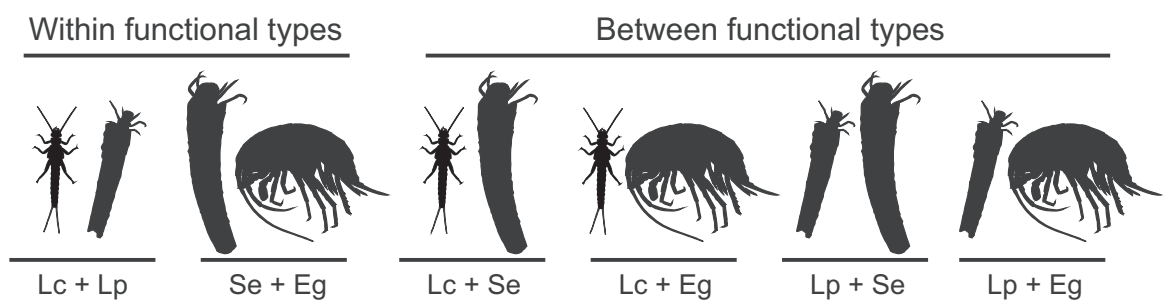

FIGURE 1 Experimental design with four detritivore species belonging to two functional types (i.e. large body- and small body-sized species) in monocultures, 2-species polycultures (six combinations of species of the same or different functional type) and the 4-species polyculture

\section{4-Species polyculture}

Between functional types

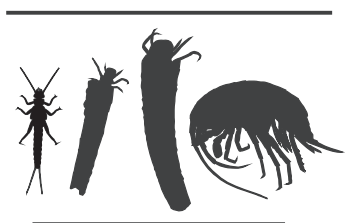

$L c+L p+S e+E g$ 
and the single 4-species polyculture), plus a control with no detritivores (Figure 1). All microcosms (except controls) had eight detritivore individuals in total (i.e. 2- and 4-species polycultures had 4 and 2 individuals per species, respectively). Each treatment (including controls) was replicated 10 times, resulting in 120 microcosms.

Plastic cups ( $13 \mathrm{~cm}$ wide, $5 \mathrm{~cm}$ deep) were used as microcosms, each containing leaf litter, substrate, $500 \mathrm{ml}$ of stream water and aeration. Litter was provided in the form of 40 discs of black alder, Alnus glutinosa [L.] Gaertn. (Betulaceae). Leaves were collected just after abscission from the forest floor in the Agüera catchment in November 2014; discs were cut with a 12-mm-diameter cork borer, air-dried and kept in the laboratory; just before the experiment, they were weighed to the nearest $0.01 \mathrm{mg}$. Substrate was provided in the form of fine sand and pebbles collected from streams, which facilitated detritivore movement and served as refuge and material for caddisfly case construction; substrate was incinerated at $550^{\circ} \mathrm{C}$ for $4 \mathrm{hr}$ and washed to remove ash before it was introduced in the microcosms. Water was taken from the stream the day before the experiment started, filtered through a $100-\mu \mathrm{m}$ mesh and added to each microcosm. Microcosms were aerated through pipette tips connected to an air injection system.

Litter discs were introduced in the microcosms 6 days before the addition of detritivores to allow leaching of soluble compounds and initial microbial conditioning. A previous experiment (Tonin et al., 2017) using a shorter conditioning period (3 days) was able to detect plant diversity effects on decomposition mediated by micro-organisms, which suggests that microbial colonization was sufficient. After this period, the water was replaced and detritivores were added. Water was again replaced on Days 7 and 14, using newly collected and filtered stream water. The experiment was terminated on Day 21, except for Sericostoma monocultures, which were terminated on Day 18 to avoid the underestimation of consumption because most of the labile litter material $(90.57 \% \pm 0.03 \mathrm{SE})$ had been consumed. Microcosms were monitored every 2 days to ensure that detritivores were alive (visual inspection without manipulation) and that there was litter remaining. We video-recorded 4-5 random microcosms with different species combinations daily $(\approx$ from 8 am to $6 \mathrm{pm}$ ) for $1 \mathrm{hr}$ each day; in total, three to four different microcosms of each species combination were video-recorded (i.e. the same microcosm was never recorded twice over the experimental period). At the end of the experiment, all litter materials [ $>1 \mathrm{~mm}$; not including fine particulate organic matter (FPOM) or faeces] were oven-dried $\left(60^{\circ} \mathrm{C}, 72 \mathrm{hr}\right)$, weighed to determine dry mass (DM), incinerated $\left(550^{\circ} \mathrm{C}, 4 \mathrm{hr}\right.$ ) and reweighed to determine ash-free dry mass (AFDM). We estimated initial AFDM using 10 additional sets of 40 litter discs.

Initial detritivore body mass for each species in each microcosm was estimated from a case length $(C L)$-body mass $(B M)$ relationship for Sericostoma $\left(B M=0.170 \times C^{2}-2.872 \times C L+14.1\right.$ $\left.54, r^{2}=0.96, n=26\right)$ and Lepidostoma $\left(B M=0.099 \times C^{2}-1.091\right.$ $\times C L+3.464, r^{2}=0.84, n=41$ ), and from a body length (BL)-BM relationship for Leuctra $\left(B M=-0.026 \times \mathrm{BL}^{2}-0.515 \times \mathrm{BL}-1.502\right.$, $\left.r^{2}=0.70, n=42\right)$ and Echinogammarus $\left(B M=0.127 \times \mathrm{BL}^{2}-1.654\right.$ $\times \mathrm{BL}+9.383, r^{2}=0.82, n=28$ ) (Supporting Information Figure S1), using additional individuals of a similar range of body mass or case length to those used in the experiment. Body length was measured from head to end of abdomen for Leuctra (i.e. excluding the cercus) and from head to end of abdomen with the body extended (i.e. not curved) for Echinogammarus. At the end of the experiment, detritivores were oven-dried $\left(60^{\circ} \mathrm{C}, 72 \mathrm{hr}\right)$ and weighed to the nearest $0.01 \mathrm{mg}$ (grouping individuals of each species from each microcosm) to determine their final body mass. Videos of detritivores were observed to investigate animal behavioural patterns that might indicate the existence of facilitation; we noted whether individuals fed on different parts of litter discs or on smaller fragments potentially produced by other species, whether individuals were more or less mobile or showed aggressive or aggregate behaviour, and whether feeding or foraging behaviour differed between monocultures and polycultures, and calculated the proportion of videos where a given species showed a particular behaviour.

\section{3 | Data analysis}

We quantified the decomposition rate mediated by detritivores (i.e. that resulting from shredding and feeding activity) as the relative daily litter mass loss $=\left[\left(L_{i}-L_{i}\right) / L M_{i}\right] / t$, where $L M_{i}$ and $L M_{f}$ were the initial and final litter AFDM in a microcosm, respectively, and $t$ was the duration of the experiment in days. Initial AFDM was previously multiplied by the average proportion of remaining mass in control microcosms $(=0.716)$ to correct for leaching and microbial losses. Detritivore growth was calculated for each species as: detritivore growth $=\left(D M_{f}-D M_{i}\right) / D M_{i}$, where $D M_{i}$ and $D M_{f}$ were the initial and final dry mass of a species in a microcosm, respectively. When there were missing individuals, their mass was estimated as the average body mass of the remaining individuals for that species in the same microcosm.

We explored hypothesis 1 using a modelling framework that explicitly quantifies the contributions of individual species and species interactions to the diversity effect (Kirwan et al., 2009). This framework included the following models (Figure 2): (1) null model (i.e. intercept only), which assumes that species perform identically and do not interact with each other; (2) species identity model, where different species have different effects on decomposition, but without interactions among species, so the performance of a polyculture can be predicted from the additive performance of each species; (3) pairwise interaction model, which augments Model 2 with interactions between pairs of species, resulting in diversity effects (i.e. a difference between the performance of a polyculture and the additive expectation from the constituent monocultures); (4) species-specific model, in which interspecific interactions are due to the presence of a particular species; (5) functional-type model, which assumes that interactions between species of different functional types (i.e. large or small species) are stronger than interactions between species within a functional type; and (6) functional similarity model, where the contributions of some species to decomposition are similar (used only when Model 5 showed no species interactions within a particular functional type). Model 6 was based in Kirwan et al.'s (2009) 


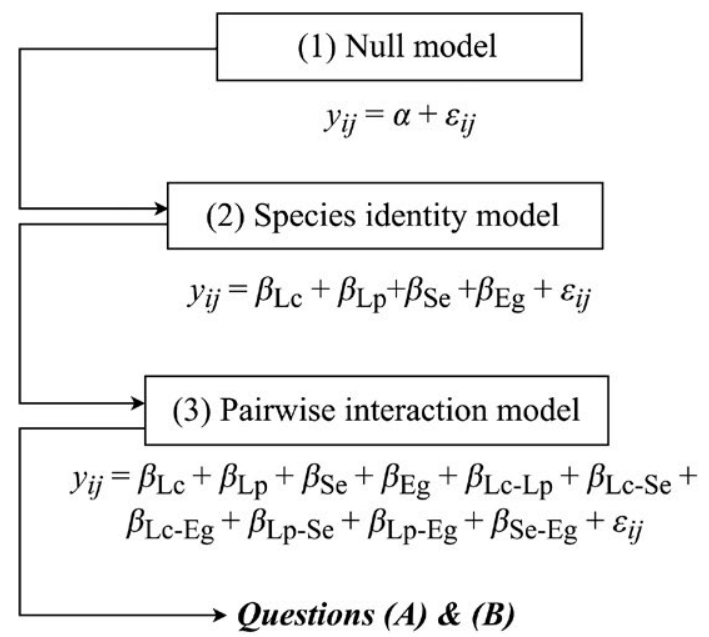

\section{Biological meaning}

All species perform similarly and do not interact

Species differ in their contribution but do not interact

Species interact to produce diversity effects

\section{(A) Is there any evidence of a species driving most interactions?}

(4) Species-specific model

$y_{i j}=\beta_{\mathrm{Lc}}+\beta_{\mathrm{Lp}}+\beta_{\mathrm{Se}}+\beta_{\mathrm{Eg}}+\beta_{\mathrm{LcINT}}+\beta_{\mathrm{LpINT}}+\beta_{\mathrm{SeINT}}+\beta_{\mathrm{EgINT}}+\varepsilon_{i j}$

(B) Is there any interaction between functional types?

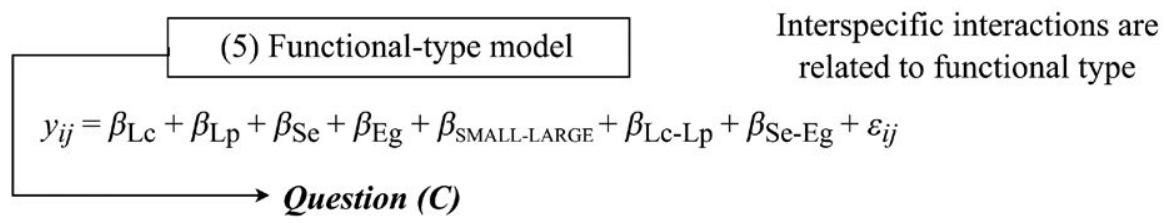

(C) Is there absence of interaction within functional types and/or similar species identity effects?

$$
y_{i j}=\beta_{\mathrm{SMALL}}+\beta_{\mathrm{Se}}+\beta_{\mathrm{Eg}}+\beta_{\mathrm{SMALL}-\mathrm{Se}}+\beta_{\mathrm{SMALL}-\mathrm{Eg}}+\beta_{\mathrm{Se}-\mathrm{Eg}}+\varepsilon_{i j}
$$

FIGURE 2 Diversity-interaction models used to test for diversity effects on decomposition. The biological meaning of each model and model terms are described next to each box; $y$, response variable; $\alpha$, intercept; $\beta$, estimated parameter of the contribution of each species; $\varepsilon_{i j}$, model residuals, which were allowed to vary with respect to each detritivore combination (see Methods). Arrows linking different boxes represent an increase in model complexity. Detritivore species: Lc, Leuctra geniculata; Lp, Lepidostoma hirtum; Se, Sericostoma pyrenaicum; Eg, Echinogammarus berilloni; 2-species polyculture interactions: Lc-Lp, Lc-Se, Lc-Eg, Lp-Se, Lp-Eg, Se-Eg; diversity-interaction terms for each species: $\mathrm{Lc}_{\mathrm{INT}}, \mathrm{Lp}_{\mathrm{INT}}, \mathrm{Se}_{\mathrm{INT}}, \mathrm{Eg}_{\mathrm{INT}}$; diversity-interaction terms for functional types: SMALL, LARGE

functional redundancy model, but did not assume functional redundancy (i.e. a $100 \%$ compensation of a species' function by another), but rather similar effects on decomposition.

The models were fitted using the "gls" function and maximum likelihood method in the NLME R package in R v.3.3.1 (Pinheiro, Bates, DebRoy, \& Sarkar, 2016; R Core Team 2016), and they were compared through a model selection procedure based on the Akaike information criterion corrected for sample size (AICc; Zuur, leno, Walker, Saveliev, \& Smith, 2009). Prior to running the models, Cleveland dotand boxplots for each response variable and species combination revealed no outliers (Zuur \& leno, 2015). As boxplots showed different variances depending on detritivore species combinations for both response variables (i.e. a violation of the homogeneity assumption for parametric models), we used the Varldent function of the NLME $R$ package in the models to produce an appropriate variance structure (Zuur et al., 2009). Due to differences in the biomass of different detritivore species, we considered correcting decomposition rates by biomass. However, polyculture:monoculture biomass ratios were not significantly different from 1 (Supporting Information Table S1), suggesting that differences between observed and expected decomposition rates in polycultures were not driven by detritivore biomass.

When significant effects of species interactions or functional types on decomposition were demonstrated, we quantified the magnitude of such effects by calculating the ratio of decomposition rate between the value of a polyculture (observed value) and the average value of the corresponding monocultures (expected value) 
(Supporting Information Appendix S1). Although we used untransformed decomposition data (because assumptions of parametric models were met after the use of appropriate variance structure; see above), log-transformed data produced similar results (Supporting Information Table S2). We further examined whether detritivore growth differed from the additive expectation (Hypothesis 2), by subtracting the relative growth of a species in a polyculture from the relative growth of the same species in a monoculture (Supporting Information Appendix S1). We calculated ordinary nonparametric bootstrapped 95\% confidence intervals ( $\mathrm{BCa}$ method using the "boot" function and package and based on 1,000 bootstrap replicates; Davison \& Hinkley, 1997; Canty \& Ripley, 2016) to test whether these intervals contained the value of 1 (for decomposition rate) or 0 (for detritivore growth)-that is, the null expectation that the response of the polyculture was not different from the mean responses of the monocultures of species present in the polyculture.

\section{3 | RESULTS}

Overall survival of detritivore species was high during the experiment ( $M \pm S E: 74 \pm 5 \%$ for Leuctra, $88 \pm 2 \%$ for Lepidostoma, $94 \pm 2 \%$ for Sericostoma and $92 \pm 2 \%$ for Echinogammarus); when different treatments were examined separately, the only incidence of low survival for Leuctra was in combination with Echinogammarus (17.5 $\pm 0.1 \%$; Supporting Information Table S3). Decomposition rates were lowest in the Leuctra monoculture $(0.69 \pm 0.10 \mathrm{mg} /$ day) and highest in the Sericostoma monoculture $(16.93 \pm 0.41 \mathrm{mg} /$ day) (Supporting Information Figure S2a; Table S4). In monocultures, Sericostoma body mass increased by $42 \%$, while Lepidostoma and Echinogammarus growth rates did not differ from zero, and body mass of Leuctra was reduced by $18 \%$ (Supporting Information Figure S2b, Table S3).

The model selection procedure showed that species interacted and produced diversity effects on decomposition rates (Supporting Information Table S5). Two models were plausible descriptions of species interactions $\left(\Delta_{i}<2\right.$; Table 1$)$ : the functional-type model and the species-specific model. The functional-type model had a better fit than the species-specific model, indicating that interspecific interactions were mostly related to detritivore body size, with some influence of species identity. The bootstrap procedure showed that interactions between functional types (i.e. small and large species) produced a $12 \%$ increase in decomposition rates of the average rate of those species in monoculture (Figure 3a). The decomposition rate of the two large species together (i.e. Sericostoma and Echinogammarus) was $19 \%$ higher than the average of their monocultures (Figure 3a). In contrast, the interaction between the two small species did not exceed the average contribution of their monocultures (Figure 3a), which led us to test for functional similarity within this functional type. However, the poor fit of the functional similarity model and the very different performances of Leuctra and Lepidostoma (see below) indicated that small organisms did not have similar effects on decomposition. The species-specific model and
TAB LE 1 Summary of model selection for the set of diversityinteraction models used to test for diversity effects on litter decomposition rate, based on the Akaike information criterion corrected for sample size ( $\mathrm{AIC}_{\mathrm{c}}$ ). Models are ordered from the best to the poorest fit according to Akaike weights $\left(w_{i}\right)$. The biological meaning of each model is described in the methods and Figure 2. $K$, number of estimated parameters for each model; $\Delta_{i}$ (delta AIC $C_{c}$, difference in $\mathrm{AIC}_{c}$ value relative to the best model; $w_{i}$ probability that a model is the best among the whole set of models. Detritivore species: Lc, Leuctra geniculata; Lp, Lepidostoma hirtum; Se, Sericostoma pyrenaicum; Eg, Echinogammarus berilloni; 2-species polyculture interactions: Lc-Lp, Lc-Se, Lc-Eg, Lp-Se, Lp-Eg, Se-Eg; diversity-interaction terms for each species: $\mathrm{Lc}_{\mathrm{INT}}, \mathrm{Lp}_{\mathrm{INT}}, \mathrm{Se}_{\mathrm{INT}}$, $\mathrm{Eg}_{\text {INT }}$; diversity-interaction terms for functional types: SMALL, LARGE

\begin{tabular}{|c|c|c|c|}
\hline Model & $\kappa$ & $\Delta_{i}$ & $w_{i}$ \\
\hline (5) Functional type & 18 & 0.00 & 0.51 \\
\hline \multicolumn{4}{|l|}{$\begin{array}{l}\mathrm{Lc}+\mathrm{Lp}+\mathrm{Se}+\mathrm{Eg}+\mathrm{S} M A L L-L A R G E+L_{c}- \\
L p+S e-E g\end{array}$} \\
\hline (4) Species-specific & 19 & 0.39 & 0.42 \\
\hline \multicolumn{4}{|l|}{$\begin{array}{l}\mathrm{Lc}+\mathrm{Lp}+\mathrm{Se}+\mathrm{Eg}+\mathrm{Lc}_{\mathrm{INT}}+\mathrm{Lp}_{\mathrm{INT}}+\mathrm{Se}_{\mathrm{INT}}+\mathrm{E} \\
\mathrm{g}_{\mathrm{INT}}\end{array}$} \\
\hline (2) Species identity & 15 & 4.78 & 0.05 \\
\hline \multicolumn{4}{|l|}{$L c+L p+S e+E g$} \\
\hline (3) Pairwise interaction & 21 & 5.82 & 0.03 \\
\hline \multicolumn{4}{|l|}{$\begin{array}{l}\mathrm{Lc}+\mathrm{Lp}+\mathrm{Se}+\mathrm{Eg}+\mathrm{Lc}-\mathrm{Lp}+\mathrm{Lc}-\mathrm{Se}+\mathrm{Lc}- \\
\mathrm{Eg}+\mathrm{Lp}-\mathrm{Se}+\mathrm{Lp}-\mathrm{Eg}+\mathrm{Se}-\mathrm{Eg}\end{array}$} \\
\hline (6) Functional redundancy & 17 & 91.89 & 0.00 \\
\hline \multicolumn{4}{|l|}{ 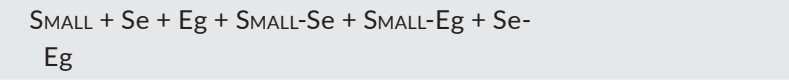 } \\
\hline (1) Null & 12 & 225.28 & 0.00 \\
\hline Intercept only & & & \\
\hline
\end{tabular}

95\% confidence intervals showed that results were not driven by the presence of a single species in a polyculture, because the effect was always higher than the additive expectation (from $9 \%$ higher in interactions with Lepidostoma to $20 \%$ higher in interactions with Sericostoma; Figure 3b).

The differences between observed and expected growth (polyculture minus monocultures) showed (i) higher growth of Lepidostoma and Leuctra when combined (Figure 3c); (ii) similar growth of Sericostoma and Echinogammarus when combined (Figure 3c); (iii) higher growth of small organisms, but similar growth of large organisms, when both small and large organisms were combined (Figure 3c); and (iv) higher overall growth of Leuctra and Lepidostoma and similar overall growth of Sericostoma and Echinogammarus (Figure 3d).

The video observations evidenced differences in feeding behaviour between monocultures and polycultures only for Leuctra, which was observed feeding on FPOM produced by other species in polycultures; the two caddisflies were observed shredding litter discs, but Lepidostoma ate only the margins, while Sericostoma ate the whole disc including the less palatable parts; Echinogammarus was a very active swimmer and was observed shredding the margins 

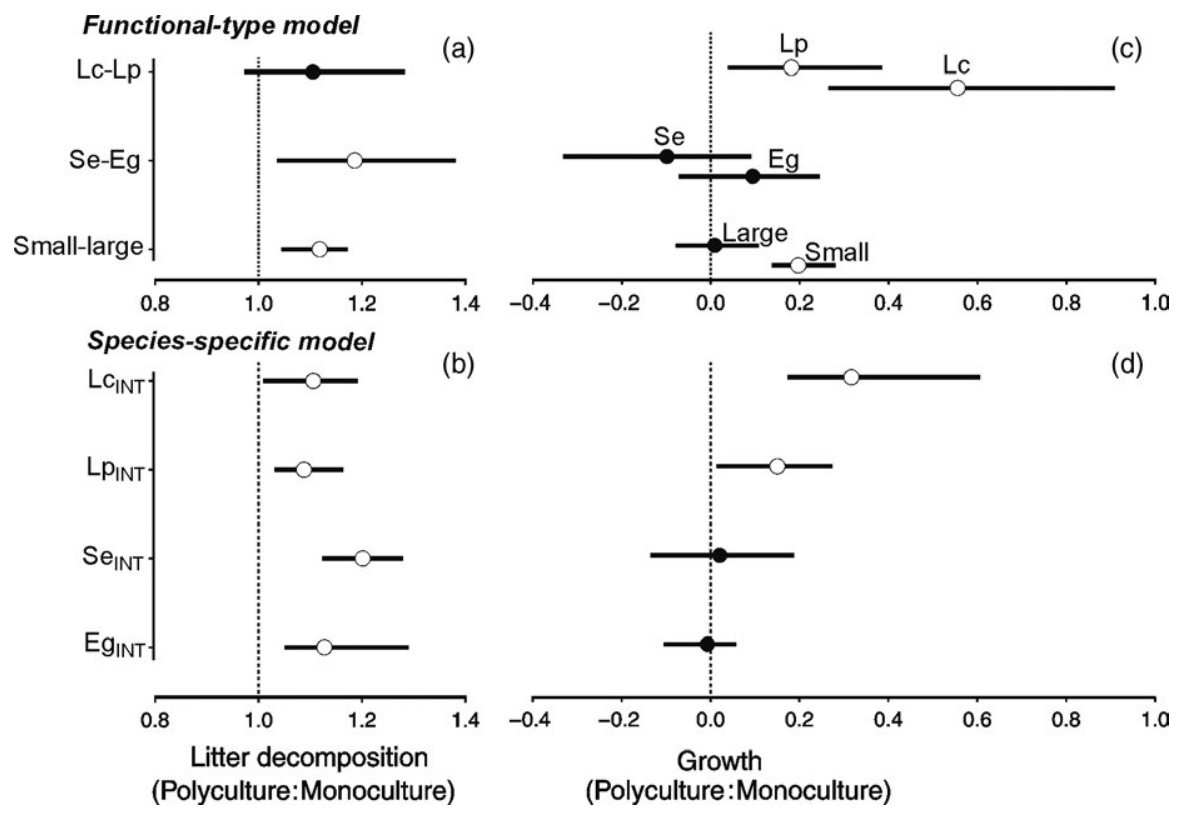

(b)

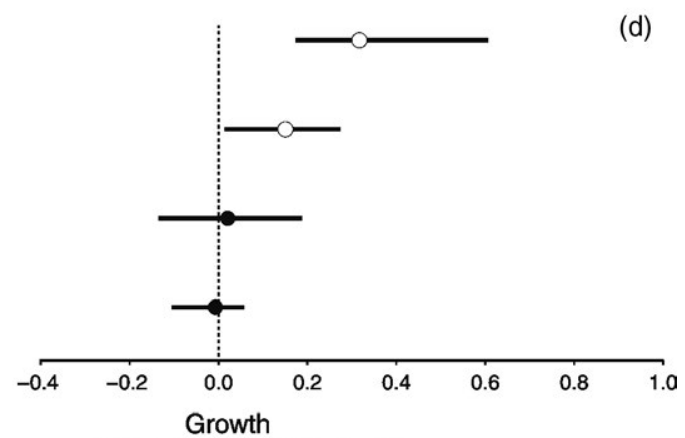

(Polyculture:Monoculture)

(Polyculture:Monoculture)

FIGURE 3 Ratio of decomposition rates between polycultures and monocultures (a, b) and difference in detritivore growth between polycultures and monocultures (c, d) for the interaction of species of similar (Lc-Lp, Se-Eg) or different body size (small-large) or for the average interaction of each species (see Figure 2 legend). The dashed line denotes the value of 1 (for decomposition) or 0 (for growth), that is, the null expectation that the polyculture value is not different from the mean value of constituent monocultures. Circles are means, and horizontal lines denote upper and lower limits of $95 \%$ nonparametric bootstrapped confidence intervals; closed circles represent intervals that do not reject the null hypothesis (i.e. do not contain the value of one or zero), and open circles represent intervals that do reject the null hypothesis

and scraping the surface of litter discs (Supporting Information Table S6).

\section{4 | DISCUSSION}

Our study is among the first to demonstrate that body size is a key trait mediating the effects of detritivore diversity on litter decomposition in streams. Reiss et al. (2011) found that within-species variation in detritivore body size had a much larger effect than diversity on decomposition rates. We show that differences in body size across species are a main determinant of interspecific interactions that mediate diversity effects on decomposition. These results are important because they can help explaining the contrasting findings of previous experiments [i.e. positive (Boyero, Pearson, \& Bastian, 2007; Constantini \& Rossi, 2010; Dangles, Jonsson, \& Malmqvist, 2002; Jonsson \& Malmqvist, 2000), negative or no effects (Bastian, Pearson, \& Boyero, 2008; Creed et al., 2009; McKie, Schindler, Gessner, \& Malmqvist, 2009; Reiss et al., 2011) of detritivore diversity on decomposition], few of which took body size into account.

We showed that diversity effects on decomposition were most evident when species of different body size were combined, which supported our first hypothesis. Leaf litter decomposed faster in polycultures containing large and small detritivores than was expected from their monocultures, indicating that interspecific interactions caused greater effects on decomposition than simple addition. Such positive effects could arise from mechanisms such as resource partitioning or facilitation, but few experimental studies have distinguished between these mechanisms (exceptions include Cardinale, Palmer, \& Collins, 2002; Jonsson \& Malmqvist, 2003). The patterns we observed suggested that facilitation was an important mechanism underlying diversity-decomposition effects, as shown by the higher growth of smaller detritivores in the presence of larger species (in support of our second hypothesis). The enhanced growth and the video observations suggested that smaller detritivores could benefit from the feeding activity of larger detritivores, which would produce large amounts of smaller litter fragments and FPOM that could be used by the small species. Leuctra species are known to act as both litter-shredding detritivores and collectors (López-Rodríguez, Tierno de Figueroa, Bo, Mogni, \& Fenoglio, 2012) and are often found in FPOM deposits in streams (Callisto \& Graça, 2013). The relatively small mouthparts of Lepidostoma compared to larger detritivores might be more efficient at handling the smaller litter fragments, although more evidence would be required to support this statement.

In contrast to the enhanced growth of small detritivores in polycultures containing species of different body size, larger detritivores showed similar growth in polycultures and monocultures, indicating that larger species did not benefit from the presence of smaller species. This could indicate that faster decomposition in polycultures was due exclusively to enhanced feeding of small species; however, this is unlikely, as the polyculture containing just the two large species also showed faster decomposition than was expected from monocultures. The absence of enhanced growth in this case, however, suggests that there was no facilitation between the large species. A plausible 
alternative mechanism underlying diversity effects on decomposition in this case would be resource partitioning, which is common among species belonging to distantly related taxa (Petchey \& Gaston, 2002), as is the case for Sericostoma and Echinogammarus, which belong to different subphyla. Gammarids are able to shred leaf litter, but can also scrape on surfaces, as observed in our videos and shown elsewhere (Mayer, Maas, \& Waloszek, 2012); in contrast, caddisflies such as Sericostoma have mouthparts that are highly specialized for fragmenting leaf material, including the tougher parts, and are more obligate leaf-eaters with gut fauna adapted to breaking down cellulose (Friberg \& Jacobsen, 1994). Thus, Sericostoma was able to eat the less palatable parts of leaf discs (minor veins), as observed in our videos and elsewhere (Tonin et al., 2017). In contrast, Echinogammarus seemed to feed only on the more palatable parts (which would better satisfy their higher energy requirements), resulting in higher consumption overall, but similar growth rates in polycultures. Also, the absence of Echinogammarus growth when in monocultures and their generalist feeding habits suggests leaf litter was not their preferred feeding resource and that their growth could be enhanced in a diverse food diet.

When the small species were together, decomposition was similar to that of the average monoculture, but growth of both species was enhanced. This suggests that facilitation occurred also between these two species, possibly through the mechanism described above: The feeding activity of Lepidostoma released high amounts of FPOM that were most likely used by Leuctra; it is also possible that Lepidostoma roughened the leaf surface, making it easier for Leuctra to eat it, as shown for other detritivores (Iwai, Pearson, \& Alford, 2009). Another plausible mechanism behind detritivore diversity effects on decomposition is the reduced density of each species, which could lead to reduced intraspecific competition for specific food resources, although there is evidence of benefits of intraspecific aggregation (McKie et al., 2009). The negative growth of Leuctra in monocultures supports the generalist feeding habit of this species (i.e. probably leaf litter is not their preferred resource) and their dependence of fine particles to enhance their growth. It is unclear, however, how Lepidostoma could benefit from the presence of Leuctra; it is possible that the presence of Leuctra somehow enhances litter quality by increasing microbial conditioning, but this would need to be tested experimentally. It is important that the positive diversity effect on decomposition found in polycultures containing large species, the distinct performance of small species in monocultures and the poor fit of the functional similarity model indicated that these species were not functionally similar. It is also noteworthy that our results were not driven by the presence of one particular species with dominant effects, unlike findings elsewhere (Dangles \& Malmqvist, 2004). However, assemblages of different species composition may produce different results due to the existence of different interspecific interactions (McKie et al., 2008) or different animal traits relevant to decomposition (e.g. feeding modes, enzymatic capabilities; Frainer, McKie, \& Malmqvist, 2014).

We conclude that body size is a key animal trait to take into account when exploring diversity effects on litter decomposition and related processes, as body size has the potential to mediate such effects through its influence on interspecific interactions. We show how different mechanisms of complementarity (i.e. facilitation and resource partitioning) can mediate interactions between detritivore species of different or similar size, and de-emphasize the existence of functional similarity between similar-sized species. Although microcosm experiments are much simpler than natural systems, these experiments are often crucial to understand complex ecological relationships (Benton, Solan, Travis, \& Sait, 2007; Fraser \& Keddy, 1999), and our results are supported by empirical evidence that body size is a key driver of many ecological processes (Peters, 1983; Woodward et al., 2005). Our study suggests that, if we are to anticipate the consequences of diversity loss for decomposition in stream ecosystems, it is crucial to take into account not only the identity and biomass of detritivore assemblages but also their body-size structure. However, our results must be interpreted with caution given the limitations of microcosm experiments-that is, the short experimental duration, lack of multigenerational responses and artificiality compared to natural systems. The applicability of our findings to real-world ecosystems can only be addressed by running longer-term experiments at different time of year with a variety of leaf litter resources, different detritivore species and a comparison with field conditions. If possible, future studies should also address the potential influence of different species' vulnerability to extinction depending on body size (Petchey, McPhearson, Casey, \& Morin, 1999; Raffaelli, 2004), and how this might affect ecosystem functioning in different scenarios of detritivore diversity (Boyero et al., 2012) and in more complex food webs (Jabiol et al., 2013; Thébault \& Loreau, 2003).

\section{ACKNOWLEDGEMENTS}

This study was funded by the "BIOFUNCTION" project (CGL201452779-P) from the Spanish Ministry of Economy and Competitiveness (MINECO) and FEDER to L.B. and J.Po., Ikerbasque start-up funds to L.B. and Basque Government funds (IT302-10) to J.Po. A.M.T. and S.M. were supported by CAPES/Science without Borders (BEX 10178/14-7) scholarship from the Brazilian Government and a scholarship from the Spanish Ministry of Economy and Competitiveness (BES2012-060743), respectively. The authors have no conflict of interests to declare.

\section{AUTHORS' CONTRIBUTIONS}

L.B. and J.Po. designed the experiment with feedback from A.M.T., S.M. and A.B.; A.M.T., S.M., L.B., A.B., J.Po. and J.Pe. conducted the field and/or laboratory work; A.M.T. and L.B. analysed the data; A.M.T. and L.B. wrote the manuscript with feedback from J.Po., R.P., B.J.C., S.M., A.B., J.Pe. and J.F.G.

\section{DATA ACCESSIBILITY}

Data available from the Open Science Framework are at: https://doi. org/10.17605/osf.io/ntm8r (Tonin et al., 2018). 


\section{ORCID}

Alan M. Tonin iD http://orcid.org/0000-0002-8463-8823

\section{REFERENCES}

Balvanera, P., Pfisterer, A. B., Buchmann, N., He, J. S., Nakashizuka, T., Raffaelli, D., \& Schmid, B. (2006). Quantifying the evidence for biodiversity effects on ecosystem functioning and services. Ecology Letters, 9, 1146-1156. https://doi.org/10.1111/j.1461-0248.2006.00963.x

Basaguren, A., Riaño, P., \& Pozo, J. (2002). Life history patterns and dietary changes of several caddisfly (Trichoptera) species in a northern Spain stream. Archiv für Hydrobiologie, 155, 23-41. https://doi. org/10.1127/archiv-hydrobiol/155/2002/23

Bastian, M., Pearson, R. G., \& Boyero, L. (2008). Effects of diversity loss on ecosystem function across trophic levels and ecosystems: A test in a detritus-based tropical food web. Austral Ecology, 33, 301-306. https://doi.org/10.1111/j.1442-9993.2007.01817.x

Benton, T. G., Solan, M., Travis, J. M. J., \& Sait, S. M. (2007). Microcosm experiments can inform global ecological problems. Trends in Ecology and Evolution, 22, 516-521. https://doi.org/10.1016/j. tree.2007.08.003

Boyero, L., Pearson, R. G., \& Bastian, M. (2007). How biological diversity influences ecosystem function: A test with a tropical stream detritivore guild. Ecological Research, 22, 551-558. https://doi.org/10.1007/ s11284-006-0303-6

Boyero, L., Pearson, R. G., Dudgeon, D., Ferreira, V., Graça, M. A. S., Gessner, M. O., ... Barmuta, L. A. (2012). Global patterns of stream detritivore distribution: Implications for biodiversity loss in changing climates. Global Ecology and Biogeography, 21, 134-141. https://doi. org/10.1111/j.1466-8238.2011.00673.x

Bruno, J. F., Stachowicz, J. J., \& Bertness, M. D. (2003). Inclusion of facilitation into ecological theory. Trends in Ecology and Evolution, 18, 119-125. https://doi.org/10.1016/S0169-5347(02)00045-9

Callisto, M., \& Graça, M. A. S. (2013). The quality and availability of fine particulate organic matter for collector species in headwater streams. International Review of Hydrobiology, 98, 132-140. https:// doi.org/10.1002/iroh.201301524

Canty, A., \& Ripley, B. (2016). boot: Bootstrap R (S-Plus) functions. R package version 1.3-18. Vienna, Austria: R Foundation for Statistical Computing.

Cardinale, B. J., Duffy, J. E., Gonzalez, A., Hooper, D. U., Perrings, C., Venail, P., ... Naeem, S. (2012). Biodiversity loss and its impact on humanity. Nature, 486, 59-67. https://doi.org/10.1038/nature11148

Cardinale, B. J., Matulich, K. L., Hooper, D. U., Byrnes, J. E., Duffy, E., Gamfeldt, L., ... Gonzalez, A. (2011). The functional role of producer diversity in ecosystems. American Journal of Botany, 98, 572-592. https://doi.org/10.3732/ajb.1000364

Cardinale, B. J., Palmer, M. A., \& Collins, S. L. (2002). Species diversity enhances ecosystem functioning through interspecific facilitation. Nature, 415, 426-429. https://doi.org/10.1038/415426a

Cardinale, B. J., Srivastava, D. S., Duffy, J. E., Wright, J. P., Downing, A. L., Sankaran, M., \& Jouseau, C. (2006). Effects of biodiversity on the functioning of trophic groups and ecosystems. Nature, 443, 989992. https://doi.org/10.1038/nature05202

Cebrian, J. (1999). Patterns in the fate of production in plant communities. The American Naturalist, 154, 449-468. https://doi. org/10.1086/303244

Constantini, M. L., \& Rossi, L. (2010). Species diversity and decomposition in laboratory aquatic systems: The role of species interactions. Freshwater Biology, 55, 2281-2295. https://doi. org/10.1111/j.1365-2427.2010.02433.x

Creed, R. P., Cherry, R. P., Pflaum, J. R., \& Wood, C. J. (2009). Dominant species can produce a negative relationship between species diversity and ecosystem function. Oikos, 118, 723-732. https://doi. org/10.1111/j.1600-0706.2008.17212.x

Dangles, O., Carpio, C., \& Woodward, G. (2012). Size-dependent species removal impairs ecosystem functioning in a large-scale tropical field experiment. Ecology, 93, 2615-2625. https://doi. org/10.1890/12-0510.1

Dangles, O., Jonsson, M., \& Malmqvist, B. (2002). The importance of detritivore species diversity for maintaining stream ecosystem functioning following the invasion of a riparian plant. Biological Invasions, 4, 441-446. https://doi.org/10.1023/A:1023698121141

Dangles, O., \& Malmqvist, B. (2004). Species richness-decomposition relationships depend on species dominance. Ecology Letters, 7, 395402. https://doi.org/10.1111/j.1461-0248.2004.00591.x

Davison, A. C., \& Hinkley, D. V. (1997). Bootstrap methods and their application. Cambridge, UK: Cambridge University Press. https://doi. org/10.1017/CBO9780511802843

Fox, J. W. (2005). Interpreting the selection effect of biodiversity on ecosystem function. Ecology Letters, 8, 846-856. https://doi. $\operatorname{org} / 10.1111 / \mathrm{j} .1461-0248.2005 .00795 . x$

Frainer, A., McKie, B. G., \& Malmqvist, B. (2014). When does diversity matter? Species functional diversity and ecosystem functioning across habitats and seasons in a field experiment. Journal of Animal Ecology, 83, 460-469. https://doi.org/10.1111/1365-2656.12142

Fraser, L. H., \& Keddy, P. (1999). The role of experimental microcosms in ecological research. Trends in Ecology and Evolution, 12, 478-481.

Friberg, N., \& Jacobsen, D. J. (1994). Feeding plasticity of two detritivore-shredders. Freshwater Biology, 32, 133-142. https://doi. org/10.1111/j.1365-2427.1994.tb00873.x

Fynke, D. L., \& Snyder, W. E. (2008). Niche partitioning increases resource exploitation by diverse communities. Science, 321, 14881490. https://doi.org/10.1126/science.1160854

Gessner, M. O., Swan, C. M., Dang, C. K., McKie, B. G., Bardgett, R. D., Wall, D. H., \& Hättenschwiler, S. (2010). Diversity meets decomposition. Trends in Ecology and Evolution, 25, 372-380. https://doi. org/10.1016/j.tree.2010.01.010

Handa, I. T., Aerts, R., Berendse, F., Berg, M. P., Bruder, A., Butenschoen, O., ... Hattenschwiler, S. (2014). Consequences of biodiversity loss for litter decomposition across biomes. Nature, 509, 218-221. https:// doi.org/10.1038/nature13247

Hooper, D. U., Chapin, F. S., Ewel, J. J., Hector, A., Inchausti, P., Lavorel, S., ... Wardle, D. A. (2005). Effects of biodiversity on ecosystem functioning: A consensus of current knowledge. Ecological Monographs, 75, 3-35. https://doi.org/10.1890/04-0922

Iwai, N., Pearson, R. G., \& Alford, R. A. (2009). Shreddertadpole facilitation of leaf litter decomposition in a tropical stream. Freshwater Biology, 54, 2573-2580. https://doi. org/10.1111/j.1365-2427.2009.02267.x

Jabiol, J., McKie, B. G., Bruder, A., Bernadet, C., Gessner, M. O., \& Chauvet, E. (2013). Trophic complexity enhances ecosystem functioning in an aquatic detritus-based model system. Journal of Animal Ecology, 82, 1042-1051. https://doi.org/10.1111/1365-2656.12079

Jiang, L., Pu, Z., \& Nemergut, D. R. (2008). On the importance of the negative selection effect for the relationship between biodiversity and ecosystem functioning. Oikos, 117, 488-493. https://doi. org/10.1111/j.0030-1299.2008.16401.x

Jonsson, M., \& Malmqvist, B. (2000). Ecosystem process rate increases with animal species richness: Evidence from leafeating, aquatic insects. Oikos, 89, 519-523. https://doi. org/10.1034/j.1600-0706.2000.890311.x

Jonsson, M., \& Malmqvist, B. (2003). Mechanisms behind positive diversity effects on ecosystem functioning: Testing the facilitation and interference hypotheses. Oecologia, 134, 554-559. https://doi. org/10.1007/s00442-002-1148-5

Kirwan, L., Connolly, J., Finn, J. A., Brophy, C., Lüscher, A., Nyfeler, D., \& Sebastia, M.-T. (2009). Diversity-interaction modeling: Estimating 
contributions of species identities and interactions to ecosystem function. Ecology, 90, 2032-2038. https://doi.org/10.1890/08-1684.1

Larrañaga, A., Basaguren, A., \& Pozo, J. (2014). Resource quality controls detritivore consumption, growth, survival and body condition recovery of reproducing females. Marine and Freshwater Research, 65, 910-917. https://doi.org/10.1071/MF13165

López-Rodríguez, M. J., Tierno de Figueroa, J. M., Bo, T., Mogni, A., \& Fenoglio, S. (2012). Living apart together: On the biology of two sympatric Leuctra species (Plecoptera, Leuctridae) in an Apenninic stream, Italy. International Review of Hydrobiology, 2, 117-123. https:// doi.org/10.1002/iroh.201111413

Loreau, M., \& Hector, A. (2001). Partitioning selection and complementarity in biodiversity experiments. Nature, 412, 72-76. https://doi. org $/ 10.1038 / 35083573$

Mayer, G., Maas, A., \& Waloszek, D. (2012). Mouthpart morphology of three sympatric native and nonnative Gammaridean species: Gammarus pulex, G. fossarum, and Echinogammarus berilloni (Crustacea: Amphipoda). International Journal of Zoology, 2012, 493420.

McKie, B. G., Schindler, M., Gessner, M. O., \& Malmqvist, B. (2009). Placing biodiversity and ecosystem functioning in context: Environmental perturbations and the effects of species richness in a stream field experiment. Oecologia, 160, 757-770. https://doi. org/10.1007/s00442-009-1336-7

McKie, B. G., Woodward, G., Hladyz, S., Nistorescu, M., Preda, E., Popescu, C., ... Malmqvist, B. (2008). Ecosystem functioning in stream assemblages from different regions: Contrasting responses to variation in detritivore richness, evenness and density. Journal of Animal Ecology, 77, 495-504. https://doi. org/10.1111/j.1365-2656.2008.01357.x

Petchey, O. L., Beckerman, A. P., Riede, J. O., \& Warren, P. H. (2008), Size, foraging, and food web structure. Proceedings of the National Academy of Sciences of the United States of America, 105, 4191-4196. https://doi.org/10.1073/pnas.0710672105

Petchey, O. L., \& Gaston, K. J. (2002). Functional diversity (FD), species richness and community composition. Ecology Letters, 5, 402-411. https://doi.org/10.1046/j.1461-0248.2002.00339.x

Petchey, O. L., McPhearson, P. T., Casey, T. M., \& Morin, P. J. (1999). Environmental warming alters food-web structure and ecosystem function. Nature, 402, 69-72. https://doi.org/10.1038/47023

Peters, R. H. (1983). The ecological implications of body-size. Cambridge, UK: Cambridge University Press.

Pinheiro, J., Bates, D., DebRoy, S., Sarkar, D. \& R Development Core Team (2016). nlme: Linear and nonlinear mixed effects models. R package.

R Core Team (2016). R: A language and environment for statistical computing. Vienna, Austria: R Foundation for Statistical Computing.

Raffaelli, D. (2004). How extinction patterns affect ecosystems. Science, 306, 1141-1142. https://doi.org/10.1126/science.1106365

Reiss, J., Bailey, R. A., Perkins, D. M., Pluchinotta, A., \& Woodward, G. (2011). Testing effects of consumer richness, evenness and body size on ecosystem functioning. Journal of Animal Ecology, 80, 1145-1154. https://doi.org/10.1111/j.1365-2656.2011.01857.x
Riaño, P. (1998). Ciclos biológicos y ecología trófica de los macroinvertebrados del bentos fluvial (Plecoptera, Ephemeroptera y Trichoptera). Bilbao, Spain: University of the Basque Country.

Scherer-Lorenzen, M. (2008). Functional diversity affects decomposition processes in experimental grasslands. Functional Ecology, 22, 547-555. https://doi.org/10.1111/j.1365-2435.2008.01389.x

Schoener, T. W. (1974). Resource partitioning in ecological communities. Science, 185, 27-39. https://doi.org/10.1126/science.185.4145.27

Srivastava, D., Cardinale, B. J., Downing, A. L., Duffy, J. E., Jouseau, C., Sankaran, M., \& Wright, J. P. (2009). Diversity has stronger top-down than bottom-up effects on decomposition. Ecology, 90, 1073-1083. https://doi.org/10.1890/08-0439.1

Thébault, E., \& Loreau, M. (2003). Food-web constraints on biodiversity-ecosystem functioning relationships. Proceedings of the National Academy of Sciences of the United States of America, 100, 1494914954. https://doi.org/10.1073/pnas.2434847100

Tonin, A. M., Boyero, L., Monroy, S., Basaguren, A., Pérez, J., Pearson, R. G., ... Pozo, J. (2017). Stream nitrogen concentration, but not plant $\mathrm{N}$-fixing capacity, modulates litter diversity effects on decomposition. Functional Ecology, 31, 1471-1481. https://doi. org/10.1111/1365-2435.12837

Tonin, A. M., Pozo, J., Monroy, S., Basaguren, A., Pérez, J., Pearson, R. G., ... Boyero, L. (2018). Data from: Interactions between large and small detritivores influence how biodiversity impacts litter decomposition. Open Science Framework. https://doi.org/10.17605/OSF.IO/NTM8R

Woodward, G., Ebenman, B., Emmerson, M., Montoya, J. M., Olesen, J. M., Valido, A., \& Warren, P. H. (2005). Body size in ecological networks. Trends in Ecology and Evolution, 20, 402-409. https://doi. org/10.1016/j.tree.2005.04.005

Wright, A. J., Wardle, D. A., Callaway, R., \& Gaxiola, A. (2017). The overlooked role of facilitation in biodiversity experiments. Trends in Ecology and Evolution, 32, 383-390. https://doi.org/10.1016/j.tree.2017.02.011

Zuur, A. F., \& leno, E. N. (2015). A beginner's guide to data exploration and visualisation with R. Newburgh, UK: Highland Statistics Ltd.

Zuur, A. F., leno, E. N., Walker, N., Saveliev, A. A., \& Smith, G. M. (2009). Mixed effects models and extensions in ecology with R. New York, NY: Springer.

\section{SUPPORTING INFORMATION}

Additional supporting information may be found online in the Supporting Information section at the end of the article.

How to cite this article: Tonin AM, Pozo J, Monroy S, et al. Interactions between large and small detritivores influence how biodiversity impacts litter decomposition. J Anim Ecol. 2018;87:1465-1474. https://doi.org/10.1111/13652656.12876 